Original Article

\title{
A DESCRIPTIVE STUDY ON QUALITY OF LIFE OF NURSES WORKING IN SELECTED HOSPITALS OF UDUPI AND MANGALORE DISTRICTS KARNATAKA, INDIA
}

\author{
Tessy Treesa Jose ${ }^{1} \&$ Sripathy M. Bhat ${ }^{2}$ \\ ${ }^{1}$ Professor \& HOD, Psychiatric/M ental Health Nursing, M anipal College of Nursing, ${ }^{2}$ Professor, Department of \\ Psychiatry, Kasturba Hospital, M anipal University, M anipal - 576 104, Karnataka, India. \\ Correspondence: \\ Tessy Treesa Jose \\ Professor \& HoD, Psychiatric/M ental Health Nursing, Manipal College of Nursing Manipal, \\ Manipal University, M anipal - 576 104, Karnataka, India. \\ E-mail : tessy.j@manipal.edu
}

\begin{abstract}
:
Quality of life (QOL) is an important dimension of health. It is a subjective term which varies from person to person and depends on each individual's capacity to cope with a situation. It is important to know how satisfied nurses are with their QOL and jobs and what characteristics influence their quality of life. The main aim of this study was to determine the Quality of Life of nurses as measured by WHO Quality of Life questionnaire and to find the association between Quality of Life and selected demographic and work related variables. The study population consisted of 1040 registered nurses working in selected medical college hospitals and government hospitals of Udupi and Mangalore districts during the period of data collection. Purposive sampling was used to select the samples. Data were gathered by administering Background proforma, and scale on Quality of life (WHO QOL-BREF). Median score of QOL of nurses on overall perception of quality of life and health were equal. Significant association was observed between Quality of life and marital status, and monthly income, area of work, working hours and total years of experience.
\end{abstract}

Keywords : Nurses, Quality of life

\section{Introduction :}

Nurses are trained to consider patient's quality of care and life but seldom their own; they rarely consider that they themselves or others in the profession may need care. Quality of working life is a system of analyzing how people experience work, how the experience relates to job satisfaction, intent to leave, turnover rate, personality and work stress ${ }^{1}$. It is now almost universally recognized that nursing is, by its very nature, a stressful occupation. Nursing was chosen as one of the occupations on which the International Labour Organization (ILO) has commissioned a manual on stress prevention ${ }^{2}$. Due to insufficient staffing,

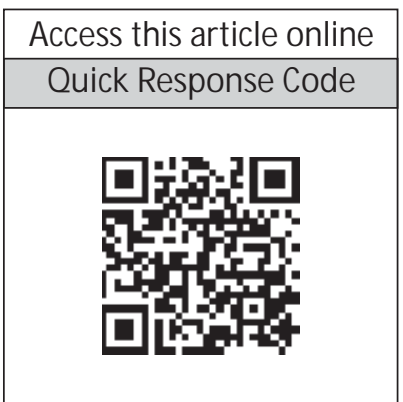
nurses experience difficulties in meeting patient needs. They become frustrated about their inability to complete their work to their professional satisfaction and express wishes to leave the nursing profession ${ }^{3}$. To cope with the challenges in the health care delivery system and to guarantee the quality of care rendered and client satisfaction on the care received, it is important to know how satisfied nurses are with their QOL and jobs and what characteristics influence their quality of life.

Ergun et al (2005) determined the quality of life of 89 oncology nurses from 12 different cities in Turkey. The study was descriptive and included Quality of life was assessed with the World Health Organization QOL Scale (WOQOL-BREF). Data were analyzed using descriptive statistics including Student t tests, analysis of variance, and the Scheffe test for post hoc analysis. M ean scores for QOL were 14.52 for the physical health domain, 14.3 for the psychological domain, 13.57 for the social relationships domain, and 11.78 for the environment domain. It has been concluded that providing care for patients with cancer has a negative impact on the QOL of oncology nurses ${ }^{4}$. 
According to World Health Organisation quality of life is defined as an individual's perception of his or her position in life in the context of the cultural and value system in which he or she lives and in relation to his or her goals, expectations, standards and concerns. Quality of life is a subjective satisfaction expressed by an individual in his physical, mental, social and spiritual situation. It is a term which varies from person to person and depends on each individual's capacity to cope with a situation (WHO, 1994). Considering the WHO concept of health as a state of physical, mental, and social wellbeing, the improvement in the quality of life of nurses becomes a very important since they have to play multiple roles in their lives. ${ }^{5}$

\section{Objectives:}

1. To determine the Quality of Life of nurses as measured byWHO Quality of Life Questionnaire (BREF).

2. To find the association between Quality of life and

2.1Demographic variables such as age, professional qualification, marital status, married status, number of children, type of family, and monthly income.

2.2 Work place variables such as area of work, daily working hours, experience in Current area of work and total years of experience.

\section{Materials and methods :}

In view of accomplishing the research objectives descriptive survey approach was considered the best. The study population consisted of the registered nurses working in selected medical college hospitals and government hospitals of Udupi and Mangalore districts during the period of data collection in 2009-2010. Purposive sampling was used to select the samples from medical college hospitals, whereas all available samples were chosen from government hospitals as the population was comparatively very less in government hospitals. Total sample size was 1040 .

\section{The following criteria were set for the selection of the sample.}

Female nurses who were:

- registered with state nursing council

- workingasstaff nurses
- involved in direct patient care

- employed at the hospital at least six months

- working in respective units at least six months

The instruments used to collect the data were Background proforma and Quality of life questionnaire (WHO QOLBREF). Background proforma had 11 items such as age, professional qualification, marital status, married status, type of family, number of children, monthly income, area of work, daily working hours, experience in current area of work and total years of experience as a nurse. The WHO, QOL- BREF is a 26-item, cross-cultural, and selfadministered scale that covers four domains of QOL (psychological, physical, social relationships and environmental). The WHOQOL-BREF contains a total of 26 questions. In addition, two items from the Overall quality of Life and General Health facet have been included, among which question one asks about an individual's overall perception of quality of life and question two asks about an individual's overall perception of their health. The four domain scores denote an individual's perception of quality of life in each particular domain. The options for the items are as follows: Item no.1\&15: Very poor, Poor, neither poor nor good, Good, Very good. Item no. 2 \& 16 25: Very satisfied, Dissatisfied, Neither satisfied nor dissatisfied, Satisfied, Very satisfied. Items 3- 9: Not at all, A little, Moderate amount, Very much, An extreme amount. Items10-14: Not at all, A little, M ostly, Completely. Item no. 26 Never, Seldom, Quite often, Very often, and Always. The scoring was 1, 2, 3, 4, and 5 for all the items except items 3 , 4 and 26 which had reverse scoring.

\section{Procedure for data collection :}

The data were collected from the registered nurses of various hospitals in Udupi and M angalore. The nurses were contacted and administered the questionnaires in their respective wards during different shifts according to their convenient time. The institutions which had continuing nursing education programme (CNE) nurses were met and data were collected soon after the CNE sessions. 


\section{Ethical considerations:}

Written permission was obtained from Dean, Manipal College of Nursing Manipal, Manipal University and also from the administrators of the institutions selected for the study. The study proposal was presented to the PhD committee of the Manipal University and ethical committee members of Kasturba hospital, Manipal and ethical clearance was sought. Permission was also sought from the administrators of the institutions from where the subjects were selected on the days of data collection, the researcher introduced herself and the purpose of the study was explained to the subjects and written consent was taken. Subject information was also provided to them. The subjects were assured of the confidentiality of the information given.

\section{Results:}

The gathered data were first coded and summarized in a master sheet and then analyzed using SPSS 16. Association between Quality of life and demographic variables and work place variables was determined by computing Kruskal-Wallis test, and M ann-Whitney (Z) test.

\section{Description of Sample characteristics:}

The sample characteristics are described in terms of frequency and percentage in table 1 and 2 .

\section{Description of Quality of life :}

This section describes the Quality of life of nurses. The WHO QOL-BREF produces a quality of life profile. Four domain scores are derived from the data. There are two items that are examined separately: question one asks about an individual's overall perception of quality of life and question two asks about an individual's overall perception of health. The four domain scores denote an individual's perception of quality of life in each particular domain. The mean score of items within each domain is used to calculate the domain score. Obtained raw scores are converted to transform scores as per the norms suggested by WHO. Advanced analysis is carried out to find the median scores of nurses in QOL dimensions with regard to demographic and work variables. The findings are presented in tables 3 - 7

\section{Association between Quality of life and selected variables}

As age was a continuous variable and did not follow normality, Spearman's rho was computed between Quality of life and age. The Spearman Rho calculated was 0.082 with $p$ value of 0.008 . Even though the correlation is statistically significant, the magnitude of the correlation coefficient is very close to zero. There is significant association between Quality of life and marital status $(p<0.001)$. Significant association is also observed between quality of life and monthly income $(p \varangle 0.001)$. Significant association is observed between Quality of life and area of work, daily working hours and total years of experience $(p<0.05)$. Findings are presented in tables 8 and 9 .

Table 1: Frequency and percentage distribution of sample characteristics with regard to demographic variables $\quad n=1040$

\begin{tabular}{|c|c|c|}
\hline \multirow{2}{*}{$\begin{array}{l}\text { Demographic variables } \\
\text { Age in years }\end{array}$} & \multicolumn{2}{|c|}{ Frequency (f) Percentage (\% } \\
\hline & & \\
\hline $21-30$ & 730 & 70.2 \\
\hline $31-40$ & 218 & 21.0 \\
\hline $41-50$ & 69 & 6.6 \\
\hline $51-56$ & 23 & 2.2 \\
\hline \multicolumn{3}{|l|}{ Professional qualification } \\
\hline General Nursing $\&$ M idwifery & 906 & 87.1 \\
\hline Basic BSc Nursing & 105 & 10.1 \\
\hline Post Certificate BSc Nursing & 29 & 2.8 \\
\hline \multicolumn{3}{|l|}{ Marital status } \\
\hline Single & 555 & 53.4 \\
\hline Married & 485 & 46.6 \\
\hline \multicolumn{3}{|l|}{ Married status } \\
\hline Staying with spouse & 326 & 67.22 \\
\hline $\begin{array}{l}\text { Staying away from spouse } \\
\text { for job purpose }\end{array}$ & 142 & 29.28 \\
\hline Divorced & 6 & 1.24 \\
\hline Widowed & 11 & 2.26 \\
\hline \multicolumn{3}{|l|}{ Type of family } \\
\hline Nuclear & 858 & 82.5 \\
\hline Joint & 182 & 17.5 \\
\hline \multicolumn{3}{|l|}{ No. of children } \\
\hline None & 84 & 17.32 \\
\hline One & 164 & 33.81 \\
\hline Two & 214 & 44.13 \\
\hline Three or more & 23 & 4.74 \\
\hline \multicolumn{3}{|l|}{ Monthly income in Rupees } \\
\hline$<5000$ & 255 & 24.5 \\
\hline $5001-9000$ & 532 & 51.2 \\
\hline $9001-13000$ & 155 & 14.9 \\
\hline$<13000$ & 98 & 9.4 \\
\hline
\end{tabular}


Table 2: Frequency and percentage distribution of sample characteristics with regard to work variables $n=1040$

\begin{tabular}{lcc}
\hline Work variables & Frequency (f) & Percentage (\%) \\
\hline Area of current work & 334 & 32.1 \\
M edical & 183 & 17.6 \\
Surgical & 111 & 10.7 \\
Operation Theatre (OT) & 154 & 14.8 \\
Intensive Care Unit (ICU) & 85 & 8.2 \\
Casuality & 52 & 5.0 \\
Special ward & 42 & 4.0 \\
Paediatrics & 56 & 5.4 \\
Obstetrics and Gynaecology & 23 & 2.2 \\
Dialysis & & \\
Daily working hours & 785 & 75.5 \\
8 & 195 & 18.8 \\
10 & 60 & 5.7 \\
12 and more & & \\
Total years of experience & 592 & 56.92 \\
1-5 & 196 & 18.85 \\
6-10 & 106 & 10.19 \\
11-15 & 92 & 8.85 \\
16-20 & 54 & 5.19 \\
>20 & & \\
Experience in current area of work & 390 & 37.5 \\
$\varangle$ One year & 348 & 33.46 \\
1-3 years & 164 & 15.77 \\
3-5 years & 138 & 13.27 \\
>5years & & \\
\hline
\end{tabular}

Table 3: Mean, Median, SD, M inimum and Maximum score of overall perception of Quality of life and health of nurses. $n=1040$

\begin{tabular}{lccccc}
\hline Items & Mean & Median & SD & $\begin{array}{c}\text { Minimum } \\
\text { Score }\end{array}$ & $\begin{array}{c}\text { Maximum } \\
\text { score }\end{array}$ \\
\hline $\begin{array}{l}\text { How do you } \\
\text { rate your }\end{array}$ & & & & & \\
$\begin{array}{l}\text { quality of life? } \\
\text { How satisfied }\end{array}$ & 3.87 & 4 & 0.62 & 1 & 5 \\
$\begin{array}{l}\text { are you with } \\
\text { your health? }\end{array}$ & 3.91 & 4 & 0.65 & 1 & 5 \\
\hline
\end{tabular}

Table 4: Domain wise M edian, SD, M inimum and M aximum score of Quality of life of nurses $n=1040$

\begin{tabular}{lcccc}
\hline Domains & Median & SD & $\begin{array}{c}\text { Minimum } \\
\text { Score }\end{array}$ & $\begin{array}{c}\text { Maximum } \\
\text { score }\end{array}$ \\
\hline Physical & 26 & 3.2 & 11 & 35 \\
Psychological & 22 & 3.1 & 7 & 29 \\
Social & 12 & 1.4 & 5 & 15 \\
Environmental & 26 & 3.8 & 5 & 38 \\
\hline
\end{tabular}

Table 5: Domain wise Means of transformed score of the Quality of the life of nurses

$n=1040$

\begin{tabular}{lccc}
\hline Domains & Raw score & $\begin{array}{c}\text { Transformed } \\
\text { score (4-20) }\end{array}$ & $\begin{array}{c}\text { Transformed } \\
\text { Score(0-100) }\end{array}$ \\
\hline Physical & 25.8 & 14.7 & 67.3 \\
Psychological & 21.5 & 14.4 & 64.9 \\
Social & 11.6 & 15.5 & 71.6 \\
Environmental & 26.5 & 13.5 & 59.4 \\
\hline
\end{tabular}

Table 6: Median scores of nurses in Quality of life dimensions by demographic variables $n=1040$

\begin{tabular}{|c|c|c|c|c|}
\hline \multirow[t]{2}{*}{ Demographic variables } & \multicolumn{4}{|c|}{ Quality of life dimension, Median (IQR) } \\
\hline & Physical & Psychological & Social & Environmental \\
\hline \multicolumn{5}{|l|}{ Age in years } \\
\hline $21-30$ & $26(24,28)$ & $22(19,24)$ & $11(11,12)$ & $26(24,29)$ \\
\hline $31-40$ & $27(27,28)$ & $22(21,24)$ & $12(12,13)$ & $27(24,30)$ \\
\hline $41-50$ & $26(24,28)$ & $21(19,23)$ & $12(11,13)$ & $26(23,28)$ \\
\hline $51-56$ & $27(25,28)$ & $23(21,24)$ & $12(12,12)$ & $28(25,30)$ \\
\hline z & 14.01 & 13.79 & 50.85 & 8.72 \\
\hline $\mathrm{p}$ & 0.003 & 0.003 & $<0.0001$ & 0.03 \\
\hline \multicolumn{5}{|l|}{ Professional qualification } \\
\hline General Nursing and Midwifery & $26(24,28)$ & $22(19,24)$ & $12(11,12)$ & $26(24,29)$ \\
\hline Basic BSc Nursing & $26(24,28)$ & $22(20,24)$ & $11(11,12)$ & $27(24,30)$ \\
\hline Post Certificate BSc Nursing & $26(24,28)$ & $23(20,24)$ & $12(11,12)$ & $27(25,30)$ \\
\hline z & 0.81 & 4.79 & 15.27 & 9.36 \\
\hline p & 0.67 & 0.09 & $<0.0001$ & $<0.0001$ \\
\hline \multicolumn{5}{|l|}{ M arital status } \\
\hline Single & $26(24,28)$ & $22(20,24)$ & $11(11,12)$ & $26(24,29)$ \\
\hline Married & $26(24,28)$ & $22(20,24)$ & $12(12,13)$ & $26(24,29)$ \\
\hline z & 2.135 & 1.184 & 14.368 & -0.785 \\
\hline$p$ & 0.03 & 0.24 & $<0.0001$ & 0.43 \\
\hline \multicolumn{5}{|l|}{ If married (Married status) } \\
\hline Staying with spouse & $26(25,28)$ & $22(20,24)$ & $12(12,13)$ & $27(24,29)$ \\
\hline Staying away from spouse & & & & \\
\hline for job purpose & $26(24,28)$ & $22(19,24)$ & $12(12,13)$ & $26(24,29)$ \\
\hline Divorced & $27(24,28.25)$ & $22.5(20,25.25)$ & $12(11.5,13)$ & $26.5(24.25,29.75)$ \\
\hline Widowed & $26(22,29)$ & $20(18,24)$ & $11(10,12)$ & $25(22,30)$ \\
\hline z & 0.54 & 2.94 & 7.43 & 2.81 \\
\hline$p$ & 0.91 & 0.40 & 0.06 & 0.4 \\
\hline
\end{tabular}




\begin{tabular}{|c|c|c|c|c|}
\hline \multirow[t]{2}{*}{ Variables } & \multicolumn{4}{|c|}{ Quality of life dimension, Median (IQR) } \\
\hline & Physical & Psychological & Social & Environmental \\
\hline \multicolumn{5}{|l|}{ Type of family } \\
\hline Nuclear & $22(24,28)$ & $26(20,24)$ & $12(11,12)$ & $27(24,29)$ \\
\hline Joint & $26(24,28)$ & $21(19,24)$ & $12(11,12)$ & $26(24,28)$ \\
\hline z & 1.97 & 1.06 & 1.37 & 1.00 \\
\hline $\mathrm{p}$ & 0.05 & 0.29 & 0.17 & 0.31 \\
\hline \multicolumn{5}{|l|}{ No. of children } \\
\hline None & $26(25,28)$ & $22(19,24)$ & $12(12,13)$ & $26(24,29)$ \\
\hline One & $26(24,28)$ & $22(20,24)$ & $12(12,13)$ & $26.5(24,30)$ \\
\hline Two & $26(24,28)$ & $22(20,24)$ & $12(12,13)$ & $27(24,29)$ \\
\hline Three or more & $28(24,29)$ & $23(21,24)$ & $12(12,13)$ & $27(25,29)$ \\
\hline z & 5.13 & 2.11 & 1.72 & 1.51 \\
\hline $\mathrm{p}$ & 0.16 & 0.55 & 0.63 & 0.67 \\
\hline \multicolumn{5}{|c|}{ Monthly income in Rupees } \\
\hline$<5000$ & $25(23,28)$ & $21(19,24)$ & $11(10,12)$ & $26(24,28)$ \\
\hline $5001-9000$ & $26(24,28)$ & $22(20,24)$ & $12(11,13)$ & $27(24,29)$ \\
\hline $9001-13000$ & $26(25,28)$ & $22(19,24)$ & $12(11,13)$ & $27(24,29)$ \\
\hline$>13000$ & $27(25,28)$ & $22(20,25)$ & $12(12,12.75)$ & $27(27,30.75)$ \\
\hline z & 17.61 & 9.83 & 57.12 & 9.86 \\
\hline $\mathrm{p}$ & 0.001 & 0.02 & $\varangle 0.0001$ & 0.02 \\
\hline
\end{tabular}

Table 7: M edian scores of nurses in Quality of life dimensions by work variables

$n=1040$

\begin{tabular}{|c|c|c|c|c|}
\hline \multirow[t]{2}{*}{ Work variables } & \multicolumn{4}{|c|}{ Quality of life dimensions, M edian(IQR) } \\
\hline & Physical & Psychological & Social & Environmental \\
\hline \multicolumn{5}{|l|}{ Area of current work } \\
\hline Medical & $26(24,28)$ & $22(19,24)$ & $12(11,12)$ & $27(24,29)$ \\
\hline Surgical & $26(23,28)$ & $22(19,24)$ & $11(11,12)$ & $27(24,30$ \\
\hline Operation Theatre(OT) & $27(25,29$ & $22(20,24)$ & $11(11,12)$ & $27(25,30)$ \\
\hline Intensive Care Unit (ICU) & $26(25,28)$ & $21(20,23)$ & $12(11,13)$ & $25.5(24,28)$ \\
\hline Casuality & $26(24,27)$ & $21(20,22)$ & $12(11,12)$ & $26(24,28.5)$ \\
\hline Special ward & $25(22.25,27)$ & $21(19,23.75)$ & $12(11,12)$ & $26(24,28.75)$ \\
\hline Paediatrics & $26.5(23.75,30)$ & $22(19,24)$ & $12(11,13)$ & $26.5(24,30.25)$ \\
\hline \multicolumn{5}{|l|}{ Obstetrics and } \\
\hline Gynaecology & $27(25,28)$ & $23(20,25)$ & $12(11,13)$ & $28(25,29.75)$ \\
\hline Dialysis & $27(24,28)$ & $23(21,24)$ & $11(10,1)$ & $27(26,30)$ \\
\hline z & 32.77 & 13.71 & 14.77 & 18.45 \\
\hline $\mathrm{p}$ & $<0.0001$ & 0.09 & 0.06 & 0.01 \\
\hline \multicolumn{5}{|l|}{ Daily working hours } \\
\hline 8 & $26(24,28)$ & $22(20,24)$ & $12(11,12)$ & $27(24,29)$ \\
\hline 10 & $25(23,27)$ & $21(19,23)$ & $11(11,12)$ & $26(23,28)$ \\
\hline 12 and more & $25(23,28)$ & $21(19,23)$ & $11(10,12)$ & $26(23,28)$ \\
\hline z & 18.28 & 10.68 & 10.134 & 9.35 \\
\hline$p$ & $<0.0001$ & 0.005 & 0.006 & 0.009 \\
\hline \multicolumn{5}{|l|}{ Total years of experience } \\
\hline $1-5$ & $26(23,28)$ & $22(20,24)$ & $11(11,12)$ & $26(24,29)$ \\
\hline $6-10$ & $26(25,28)$ & $21(19,23.75)$ & $12(11,13)$ & $26(24,28)$ \\
\hline $11-15$ & $27(25,28)$ & $22(21,24)$ & $12(11,13)$ & $28(25,30)$ \\
\hline $16-20$ & $27(25,29)$ & $22(20,24)$ & $12(11.25,13)$ & $27(24,30)$ \\
\hline$>20$ & $26(24,28)$ & $21(20,24)$ & $12(11,12)$ & $26(24,29)$ \\
\hline $\mathrm{z}$ & 20.81 & 8.55 & 67.27 & 8.91 \\
\hline $\mathrm{p}$ & $<0.0001$ & 0.07 & $<0.0001$ & 0.06 \\
\hline
\end{tabular}




\begin{tabular}{lllll}
\hline Work variables & \multicolumn{3}{l}{ Quality of life dimensions, Median(IQR) } & \\
\cline { 2 - 5 } & Physical & Psychological & Social & Environmental \\
\hline Experience in current area of work & & & & \\
¿ne year & $26(26,28)$ & $22(20,24)$ & $11(11,12)$ & $26(24,29)$ \\
1-3 years & $26(24,28)$ & $22(19,24)$ & $11(11,12)$ & $27(24,29)$ \\
3-5 years & $27(24,28)$ & $22(20.25,24)$ & $12(11,13)$ & $26(24,29)$ \\
$>$ 5years & $26(25,28)$ & $22(20,24)$ & $12(11,12.25)$ & $27(24,29)$ \\
$z$ & 4.14 & 4.97 & 20.22 & 0.91 \\
$p$ & 0.25 & 0.17 & $\varangle 0.0001$ & 0.82 \\
\hline
\end{tabular}

Table 8: M edian, IQR, Test statistic, df and $p$ value of Quality of life and demographic variables of nurses

$n=1040$

\begin{tabular}{|c|c|c|c|c|}
\hline Demographic variables & Median & Inter quartile range & Test statistic \& df & $p$ value \\
\hline \multicolumn{5}{|l|}{ Professional qualification } \\
\hline GNM & 86 & $80-91$ & & \\
\hline BBSC & 87 & 80-91.5 & 2.79 & 0.25 \\
\hline PCBSC & 88 & $82.5-93$ & 2 & \\
\hline \multicolumn{5}{|l|}{ M arital status } \\
\hline Single & 85 & $79-90$ & 3.52 & $\varangle 0.001$ \\
\hline Married & 88 & $82-92.25$ & 1 & \\
\hline \multicolumn{5}{|l|}{ If married(Married status) } \\
\hline Staying with spouse & 88 & $82-92.25$ & & \\
\hline Staying away from spouse & 85.5 & 81-92 & 3.005 & 0.39 \\
\hline Divorced & 89 & $79.25-96$ & 3 & \\
\hline Widowed & 81 & $75-93$ & & \\
\hline \multicolumn{5}{|l|}{ Type of family } \\
\hline Nuclear & 86 & $80-91$ & 0.04 & 0.97 \\
\hline Joint & 85 & $80-92$ & 1 & \\
\hline \multicolumn{5}{|l|}{ No.of children } \\
\hline None & 87 & $81.25-94$ & & \\
\hline One & 87 & $81-93.75$ & 3.32 & 0.35 \\
\hline Two & 87 & $80-91$ & 3 & \\
\hline Three or more & 85 & $79-90$ & & \\
\hline \multicolumn{5}{|l|}{ Monthly income in Rs } \\
\hline$<5000$ & 84 & $78-90$ & & \\
\hline $5001-9000$ & 86.5 & $81-92$ & 19.12 & $\varangle 0.001$ \\
\hline $9001-13000$ & 87 & $79-92$ & 3 & \\
\hline$>13000$ & 85 & $80-91.25$ & & \\
\hline
\end{tabular}

Table 9: M edian, IQR, Test statistic, df and $p$ value of Quality of life and work variables of nurses

\begin{tabular}{lcccc} 
& \multicolumn{2}{c}{$\mathrm{n}=1040$} \\
\hline Work variables & Median & Inter quartile range & Test statistic \& df & p value \\
\hline Area of work & & & & \\
$\quad$ Medical & 86 & $79-91$ & 22.04 & \\
Surgical & 86 & $790-91$ & 8 & \\
Operation theatre & 88 & $812-93$ & \\
Intensive care unit & 85 & $78.50-89$ & \\
Casuality & 85 & $81-90.25$ & \\
Special ward & 84 & $78-91$ & \\
Paediatrics & 88 & $77.50-95.50$ & \\
OBG & 90 & $82 .-94$ & \\
Dialysis & 88 & $83-92$ & \\
\hline
\end{tabular}




\begin{tabular}{|c|c|c|c|c|}
\hline Work variables & Median & Inter quartile range & Test statistic $\&$ df & pvalue \\
\hline \multicolumn{5}{|c|}{ Daily working hours } \\
\hline 8 & 87 & $81-92$ & 19.38 & $\varangle .001$ \\
\hline 10 & 84 & 77-89 & 2 & \\
\hline 12 and more & 83 & $78-88.75$ & & \\
\hline \multicolumn{5}{|c|}{ Total years of experience } \\
\hline $1-5$ & 85.5 & $79-90$ & 17.39 & 0.002 \\
\hline $6-10$ & 85 & $79.25-91$ & 4 & \\
\hline $11-15$ & 88 & $82.75-93$ & & \\
\hline $16-20$ & 89 & $81.25-93$ & & \\
\hline$>20$ & 87 & $81-92.50$ & & \\
\hline \multicolumn{5}{|c|}{ Experience in current area of work } \\
\hline$<1$ & 85 & 79-91 & 4.72 & 0.2 \\
\hline $1-3$ & 86 & $80-91$ & 3 & \\
\hline 3-5 & 86 & $81-92$ & & \\
\hline$>5$ & 87 & $81-92$ & & \\
\hline
\end{tabular}

\section{Discussion :}

In the present study median scores (4) of nurses' overall perception of quality of life and general health were equal with the mean score $3.87 \pm 0.62$ and $3.91 \pm 0.65$ respectively. Similar finding is reported by Ergun (2005) where mean scores of QOL were $2.07+0.69$ for perceived general QOL and $3.34 \pm 0.78$ for perceived general health. Supportive findings are also reported by Cimet (2003) who conducted a study to determine whether there is a relation between job satisfaction and quality of life with the mean score of 2.8 and 3.22 for the perceived general QOL and perceived general health respectively ${ }^{6}$. The reason for having similar findings may be because all these three studies used the same standardized to ol (WHOQOL-BREF).

In the present study with raw score of quality of life of nurses, environmental domain obtained the highest score $(26.5 \pm 3.8)$ and social domain obtained the lowest score $(11.6 \pm 1.4)$, whereas in the transformed score within the range of 4-20, social domain obtained the highest (15.5 \pm 1.85) score while the environmental domain had the lowest score $(13.5 \pm 1.93)$. The physical and psychological domain scores were $14.74 \pm 1.86$, and $14.4 \pm 2.1$ respectively. This finding is in agreement with Lee $\mathrm{J} I$ et.al (2004) who identified correlations between fatigue and quality of life in clinical nurses and found highest score in the social domain of Quality of life followed by physical, psychological, and environmental domains ${ }^{7}$. This reveals that nurses in these studies are satisfied with their personal relationship, sex life and support from their friends. Like in the present study QOL was assessed in this study by using the same QOLscale.

In the study conducted by Alfaia dos Santos, Beresin $(2009)^{8}$ the environmental domain obtained the highest score (27.08) and social domain obtained the lowest score (11.37), which supports the present study. With transformed score of QOL also environmental domain obtained the highest score (19.33) and psychological domain obtained the lowest score (13.99), which is contrary to the present study findings. The study being referred to was done among only Operation room (OR) nurses with the sample of 24 . The hospital in this study was a large private hospital with a qualified modern structure that offers its employees some benefits, such as health care plan, transport service, day care facilities for employees' children etc, whereas none of these facilities except health care plan in few hospitals were available for the population under present study. The pay received by the nurses under present study is comparatively less than the salary of the nurses in other countries. Due to the severe shortage of nurses, the subjects in the present study are not in a position to take their break or leisure time during duty

Study conducted by Ergun (2005) tallies with the present study finding where environmental domain (11.8 \pm 1.94$)$ had the lowest score. The highest score was in physical domain (14.52 \pm 2.18$)$ which differs from the finding of 
present study. Study conducted by Cimet $(2003)^{16}$ also agrees with the present study for the minimum score in environmental domain (11.2).

In the present study significant association was found between quality of life and marital status, monthly income, area of work, working hours and total years of experience $(p=\measuredangle 0.05)$. Similar findings are reported by Cimet (2003) who found significant association between quality of life

\section{References:}

1. Ansari, AH. Quality of work life, a comparative study of teachers. Indian Psychological Review.1997; 49(3).

2. World Health Organisation. Psychosocial factors at work: Recognition and control, Occupational safety and health Series No. 56. Report of the Joint ILO/WHO Committee on Occupational Health Ninth Session, Geneva, and 18-24 September 1984 Available from http://www.ilo.org/ public/libdoc/ilo/1986/86 B09_301_engl.pdf.

3. Hegney D, Plank V, Parker V. Nursing workloads: the results of a study of Queensland nurses, Journal of Nursing Management. 2003; 11(5):307-314.

4. Ergun FS, Oran NT, and Bender CM. Quality of life of oncology nurses. Cancer Nursing. 2005 M ay-Jun; 28(3):193-9.

5. The WHOQoL Group. The development of the World Health Organization Quality of Life Assessment Instrument. Quality of Life Assessment: International Perspectives. In J. Orley and W. Kuyken (Eds). Heidleberg: Springer-Verlag: 1994a.

6. Cimete G, Gencalp NS, Keskin G. Quality of life and job satisfaction of nurses. Journal of Nursing Care Quality. 2003 Apr-Jun; 18(2):151-8.

7. Lee JI, Park SH, M oon JM , Park KA, Kim KO, Jeong HJ, Jung JY .Fatigue and Quality of Life in Clinical Nurses. J Korean Acad Fundam Nurs. 2004 Dec; 11(3):317-326.

8. Alfaia dos Santos RM, Beresin R. Quality of life of nurses in the operating room. Einstein. 2009; 7 (1)152-8. and age, economic level, marital status, and duration of working life. Present study finding did not show any significant association between QOLand age.

\section{Acknowledgement:}

Authors are thankful to the administrators of the selected institutions and the nurses who participated in the study willingly. 